\title{
The effect of inlet and outlet boundary conditions in image-based CFD modeling of aortic flow
}

\author{
Sudharsan Madhavan ${ }^{*}$ (i) and Erica M. Cherry Kemmerling
}

\author{
${ }^{*}$ Correspondence: \\ sudharsan.madhavan@tufts. \\ edu \\ Department of Mechanical \\ Engineering, Tufts University, \\ 200 College Avenue, \\ Medford, MA 02155, USA
}

\begin{abstract}
Background: Computational modeling of cardiovascular flow is a growing and useful field, but such simulations usually require the researcher to guess the flow's inlet and outlet conditions since they are difficult and expensive to measure. It is critical to determine the amount of uncertainty introduced by these assumptions in order to evaluate the degree to which cardiovascular flow simulations are accurate. Our work begins to address this question by examining the sensitivity of flow to several different assumed velocity inlet and outlet conditions in a patient-specific aorta model.
\end{abstract}

Methods: We examined the differences between plug flow, parabolic flow, linear shear flows, skewed cubic flow profiles, and Womersley flow at the inlet. Only the shape of the inlet velocity profile was varied - all other parameters were identical among these simulations. Secondary flow in the form of a counter-rotating pair of vortices was also added to parabolic axial flow to study its effect on the solution. In addition, we examined the differences between two-element Windkessel, three element Windkessel and the outflow boundary conditions. In these simulations, only the outlet boundary condition was varied.

Results: The results show axial and in-plane velocities are considerably different close to the inlet for the cases with different inlet velocity profile shapes. However, the solutions are qualitatively similar beyond $1.75 D$, where $D$ is the inlet diameter. This trend is also observed in other quantities such as pressure and wall shear stress. Normalized root-mean-square deviation, a measure of axial velocity magnitude differences between the different cases, generally decreases along the streamwise coordinate. The linear shear inlet velocity boundary condition and plug velocity boundary condition solution exhibit the highest time-averaged wall shear stress, approximately $8 \%$ higher than the parabolic inlet velocity boundary condition. Upstream of 1D from the inlet, adding secondary flow has a significant impact on temporal wall shear stress distributions. This is especially observable during diastole, when integrated wall shear stress magnitude varies about $26 \%$ between simulations with and without secondary flow. The results from the outlet boundary condition study show the Windkessel models differ from the outflow boundary condition by as much as $18 \%$ in terms of time-averaged wall shear stress. Furthermore, normalized root-mean-square deviation of axial velocity magnitude, a measure of deviation between Windkessel and the outflow boundary 
condition, increases along the streamwise coordinate indicating larger variations near outlets.

Conclusion: It was found that the selection of inlet velocity conditions significantly affects only the flow region close to the inlet of the aorta. Beyond two diameters distal to the inlet, differences in flow solution are small. Although additional studies must be performed to verify this result, the data suggest that it is important to use patientspecific inlet conditions primarily if the researcher is concerned with the details of the flow very close to the inlet. Similarly, the selection of outlet conditions significantly affects the flow in the vicinity of the outlets. Upstream of five diameters proximal to the outlet, deviations between the outlet boundary conditions examined are insignificant. Although the inlet and outlet conditions only affect the flow significantly in their respective neighborhoods, our study indicates that outlet conditions influence a larger percentage of the solution domain.

Keywords: Inlet boundary conditions, Womersley, Windkessel, Outlet boundary conditions

\section{Background}

Cardiovascular computational fluid dynamics (CFD) models have the ability to aid physicians in non-invasive diagnostic decision making, and over the past decade, commercial, patient-specific modeling has become more common owing to numerous advancements in computing speed [1], medical image acquisition, and 3D data processing and visualization techniques [2-5].

Cardiovascular diseases (CVDs) are the leading cause of death globally [6], with the most common conditions including coronary artery disease (CAD), stroke, heart failure, rheumatic heart disease, heart arrhythmia, aortic aneurysms, and thromboembolic diseases [6, 7]. CAD and stroke account for about 77\% of CVD deaths [6], but many other conditions contribute to impairment or decreased quality of life of the patient. As a means to diagnosing and understanding these conditions, commercial, patient-specific modeling of CVDs has become more common in recent years. For instance, HeartFlow, Inc., Redwood City, California has developed a non-invasive CFD-based tool to identify lesions causing ischemia [8, 9]. Another application of cardiovascular CFD is designing new surgical techniques and implantable medical devices [10, 11]. Procedures and devices have traditionally been validated via clinical trials, animal tests, and evaluation of patients post-surgery. Cardiovascular modeling is now increasingly aiding these developments [11-18]. For example, [10] designed a 'virtual surgery' for pediatric surgeons based on patient-specific images. Their framework also computed post-operative hemodynamics based on the virtual surgery, thereby aiding surgeons in surgical planning. Furthermore, hemodynamic alterations are known to be a significant cause of ischemic disease progression [19]. Owing to these uses and other promising applications, there is a substantial need for accurate modeling of cardiovascular flows.

Unfortunately, much of the information required to perform accurate cardiovascular CFD is usually unavailable due to the difficulty of making in vivo flow measurements on live patients. Consequently, in order to formulate a well-posed problem, most researchers must guess parameters such as flow boundary conditions, vessel wall properties, and sometimes even geometric vessel parameters if patient imaging is not of sufficient quality. It has been shown that these factors and others can significantly alter the flow 
solution [20-25]. For example, $[25,26]$ performed a numerical study to quantify the sensitivity of wall shear stress fields in the carotid bifurcation to geometric and secondary flow perturbations. They found that small geometric variations could significantly affect the flow solution. Sankaran et al. [27] quantified uncertainties due to geometry, boundary conditions, and blood viscosity in coronary blood flow simulations using a stochastic collocation method [28]. They concluded that solutions from modeling were most sensitive to variations in minimum lumen diameter. Sankaran et al. [29] developed a reduced-order model based on a machine learning approach to quantify uncertainties due to geometric variations. They found that larger arteries with significant stenosis were most sensitive to geometric variations. Liu et al. [19] modeled a patient-specific circle of Willis coupled with a zero-dimensional lumped parameter boundary condition. They determined that the accuracy and consistency of their method were improved relative to a resistance-based boundary condition. Steinman et al. [22] was a collective study by 25 research groups to predict the variability of pressure drop in a giant aneurysm model with a proximal stenosis. Various research groups performed CFD analysis with the same lumen geometry, flow rates, and fluid properties. However, the researchers were free to choose their own numerical methods, discretization, and solution strategies. They concluded that pressure could be predicted with reasonable accuracy by CFD in the giant aneurysm model but transitional patterns and derived quantities varied widely. Liu et al. [30] developed a new methodology for functional assessment of stenotic carotid arteries. Their methodology based on thresholding pressure gradient successfully delineated severe stenosis from mild-moderate ones. Xiong et al. [31] investigated the effect of blood pressure variability on carotid atherosclerotic plaques. They determined that beat-to-beat blood pressure variability could severely exacerbate longterm outcomes of atherosclerosis. Wong et al. [32] studied the effect of fluid structure interaction on carotid bifurcation models with varying degrees of atherosclerosis. They concluded that wall shear stress and geometric deformation are significantly influenced by the severity of the disease. Liu et al. [33] simulated fluid structure interaction of blood flow and elastic arteries with eccentric stenotic plaques. They showed that wall shear stress, pressure drop and von Mises stress were positively correlated with the degree of vessel occlusion via plaques. Pekkan et al. [23] examined variations between solutions from a first-order accurate commercial software and a second-order accurate in-house flow solver. Only the second-order methods could accurately match the three-dimensional flow features found in an experimental model. Recent studies [20, 21] showed the effect of mesh resolution on patient-specific models and concluded that a typical mesh resolution in comparison to a higher mesh resolution resulted in pronounced underestimation of quantities such as wall shear stress and oscillatory shear index. They also showed that higher resolution meshes were able to capture flow instabilities.

Since cardiovascular CFD simulations are used to make critical decisions in diagnosis [30], surgical planning [10], and medical device designs [12, 13, 15], it is essential to verify that the assumptions made by the researcher do not negatively impact the fidelity of the solution. In this paper, we focus on the impact on flow solution of assumed inlet velocity boundary conditions in the human aorta. Some have argued that researchers concerned about the choice of inlet conditions should merely extend the size of the simulation domain so the flow is fully-developed by the time it reaches the point of interest. 
However, this is rarely a realistic solution since real arteries are poorly approximated by long, straight tubes, thus the flow is never truly fully-developed within the body. Furthermore, it is often prohibitively complex to add realistic upstream sections of the vasculature, as in the case of the aorta, which is immediately distal to the heart.

The aorta is of particular interest not only due to its position proximal to all other arteries, but also because invasive and non-invasive experimental measurements on the aortic arches of animals and humans have reported wide variations in the shape of the velocity profile, including flat [34], skewed [35], and highly patient-specific [36]. Consequently, in cases where patient-specific profiles are unavailable, the optimal profile shape to assume is not clear, and researchers have made many different choices [37-44]. To our knowledge, it is thus far undetermined to what extent the researcher's choice of aortic inlet boundary condition changes the solution, or how far distal to the inlet the flow is significantly affected by the choice of inlet condition. In addition, it is not always clear how the choice of outlet boundary condition affects the flow solution; most researchers choose between an outflow outlet condition, in which flowrate is specified at each outlet, and a Windkessel model, in which distal resistances and capacitances are modeled [45-49]. It is critical to answer these questions to determine the extent to which the hundreds of published studies with non-patient-specific inlet and outlet conditions are accurate. In the current study, we begin to address these issues by simulating aortic flow with a variety of idealized inlet and outlet conditions. At the inlet, we examine plug flow, parabolic flow with and without secondary flow, linear shear flows, skewed cubic profiles, and Womersley flow. At the outlet, we study the two-element and threeelement Windkessel models and compare them with specified mass flow rate and zero diffusion flux (ANSYS ${ }^{\circledR}$ Academic Research [Fluent], release 16.2, outflow boundary conditions, ANSYS, Inc.). The overall goal is to quantify the differences in flow solution caused by choice of inlet and outlet conditions for the purposes of evaluating the impact of assumed boundary conditions on previously-published aortic flow studies.

\section{Methods}

An image-based model of a patient-specific aorta of a healthy adult including the brachiocephalic trunk, common carotid arteries, and subclavian arteries was obtained through a personal correspondence (A. Marsden, personal communication, January 11, 2016). A perspective view of the model is shown in Fig. 1a.

The commercial CFD software package ANSYS Fluent (ANSYS ${ }^{\circledR}$ Academic Research [Fluent], release 16.2) was used for our analysis. The built-in ANSYS meshing tool was employed to discretize the patient-specific geometry using tetrahedral grid elements. We solved the incompressible 3D Navier-Stokes equations shown in Eq. 1 using a finite volume discretization. While the pressure was computed using a second order discretization, the momentum was determined employing a second order upwind scheme. Pressure and velocity were coupled following the Semi-Implicit Method for Pressure Linked Equations (SIMPLE) algorithm [50], (ANSYS $^{\circledR}$ Academic Research [Fluent], release 16.2, 25.9.1, Choosing the PressureVelocity Coupling Method, ANSYS, Inc.). We required the scaled residual criteria defined in $\left(A N S Y S^{\circledR}\right.$ Academic Research [Fluent], release 16.2, 25.18.1, Monitoring Residuals, ANSYS, Inc.) to be less than $10^{-3}$ for convergence. This corresponds 


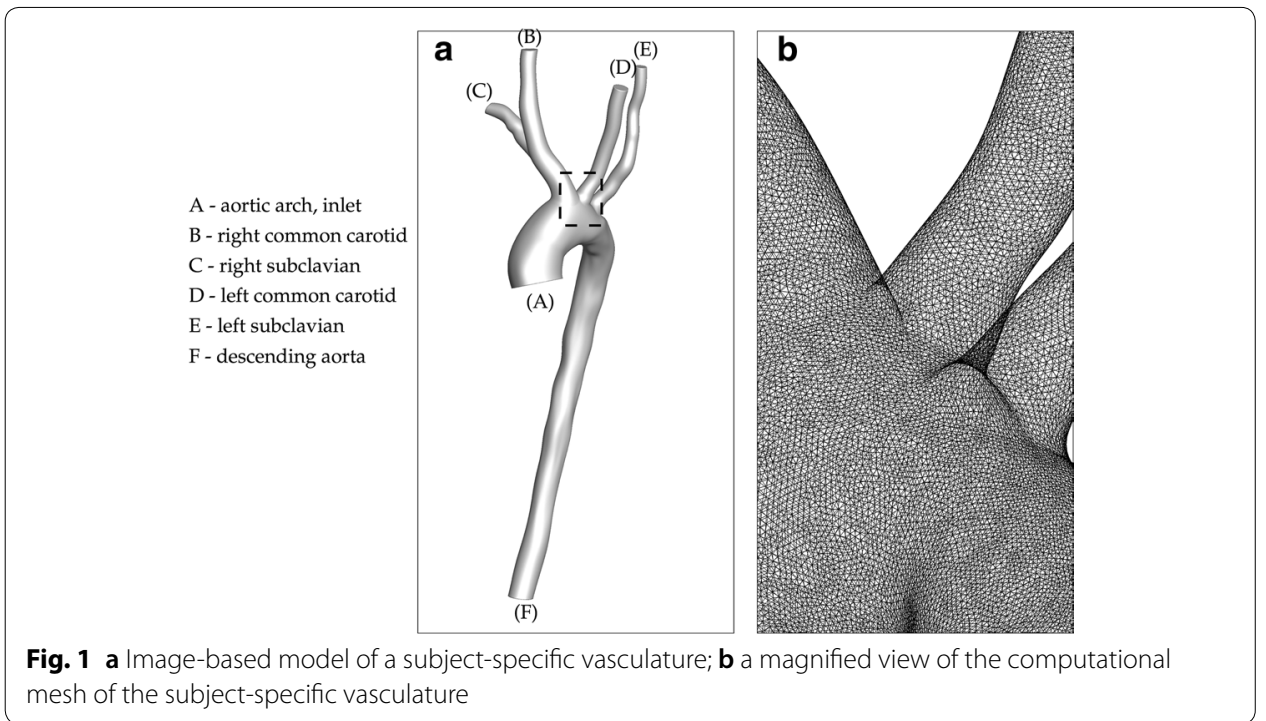

conceptually to a percentage error of less than $0.1 \%$ in the solution to the NavierStokes equations and is consistent with the recommendation from $\left(A N S Y S^{\circledR}\right.$ Academic Research [Fluent], release 16.2, ANSYS, Inc.). Blood was modeled as a Newtonian fluid with a density of $1060 \mathrm{~kg} / \mathrm{m}^{3}$ [51] and a viscosity of $0.004 \mathrm{~Pa} \mathrm{~s}$ [52]. Although Newtonian models consistently underestimate significant physiological factors such as wall shear stress, the qualitative patterns have been shown to be similar to those predicted by non-Newtonian models [53-58]. In particular, the average difference in wall shear stress between Newtonian and non-Newtonian models, as demonstrated by $[57,58]$, is about $10 \%$. We also assumed the vessel walls to be rigid, which has been shown to overestimate quantities such as instantaneous wall shear stress. However, time-averaged wall shear stress has been shown to vary by only about 4.5\% [59-61]. Moreover, this work is an attempt to study the effect of varying inlet boundary conditions along with the most commonly assumed parameters in cardiovascular simulations [62-66], rather than to perform an optimally realistic simulation of aortic flow.

$$
\begin{aligned}
\frac{\partial u_{i}}{\partial t}+u_{j} \frac{\partial u_{i}}{\partial x_{j}} & =-\frac{1}{\rho} \frac{\partial p}{\partial x_{i}}+v \frac{\partial^{2} u_{i}}{\partial x_{j} \partial x_{j}} \\
\frac{\partial u_{j}}{\partial x_{j}} & =0
\end{aligned}
$$

In the present study, 6,484,130 tetrahedral elements were used to discretize the geometry with a minimum element size of $6.98 \times 10^{-5} \mathrm{~m}$ and a maximum element size of $2.52 \times 10^{-4} \mathrm{~m}$. Doubling the number of elements contributed to only about $1.8 \%$ rootmean-square (RMS) differences in the velocity magnitude. A zoomed-in section of the grid is shown in Fig. 1b. Temporally, we employed a first order implicit scheme with a time step of $0.01 \mathrm{~s}$. This scheme was found to be both stable and efficient with our model in comparison to the other options. 


\section{Inlet sensitivity studies}

In the first part of this study, the sensitivity of flow solutions to velocity inlet conditions was investigated. For these simulations, a zero diffusion flux for all flow variables at the outlets and an overall outlet flow rate were employed to impose specified \% mass flow splits $\left(A N S Y S^{\circledR}\right.$ Academic Research [Fluent], release 16.2, 7.3.10, outflow boundary conditions, ANSYS, Inc.). The average outflow rates were obtained from [45, 67].

The average outlet flow rates in the daughter vessels are shown in Table 1. Inlet boundary conditions in the model were set up using user-defined functions (UDFs). An external code (in $\mathrm{C}++$ ) was written to generate custom inlet velocity boundary conditions. The total flow rate vs. time waveform, shown in Fig. 2, was adapted from [68]. Eighth order Fourier decomposition of the aforesaid waveform was used in the current study. For the different simulation cases, the shape of the inlet velocity profile was varied without changing the flow rate. Plug flow, parabolic flow, linear shear flows, skewed cubic flow profiles, and Womersley flow were examined. A schematic of all the primary flow inlet conditions examined except the Womersley condition is shown in Fig. 3. Womersley flow with an identical flow rate was modeled following the formulations of [69]. In addition to the aforementioned conditions, a parabolic primary inlet flow with a counter-rotating vortex pair secondary flow was simulated. The numerical formulation of this secondary flow is described by Eqs. 2 and 3. The mean secondary flow speed was $24 \%$ of the mean primary flow speed, as reported in [70], during the systolic periods. Realistic secondary flow in some vessels can be modeled by adding a simple proximal geometry extension, as is done for coronary arteries in [25]. However, such a model is not accurate

Table 1 Outflow boundary conditions

\begin{tabular}{lc}
\hline Vessel & Outlet flow rate \\
\hline B-right common carotid & 9.8 \\
C-right subclavian & 9.5 \\
D-left common carotid & 5.2 \\
E-left subclavian & 6.4 \\
F-descending aorta & 69.1 \\
\hline
\end{tabular}

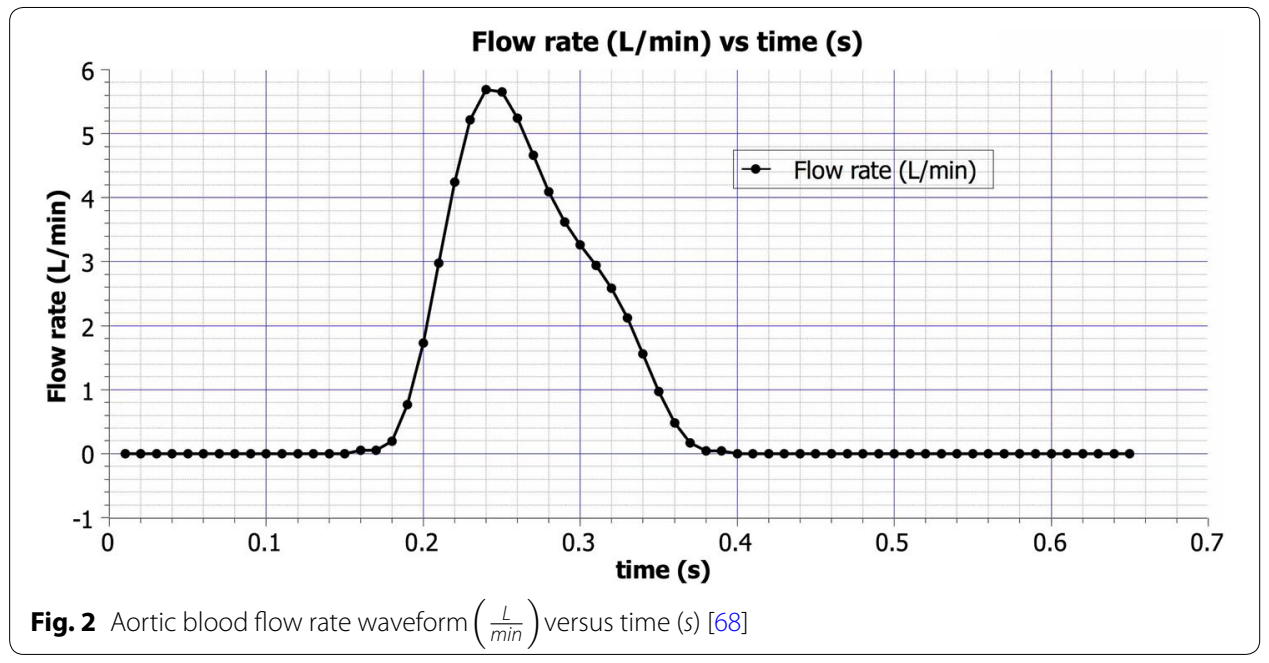



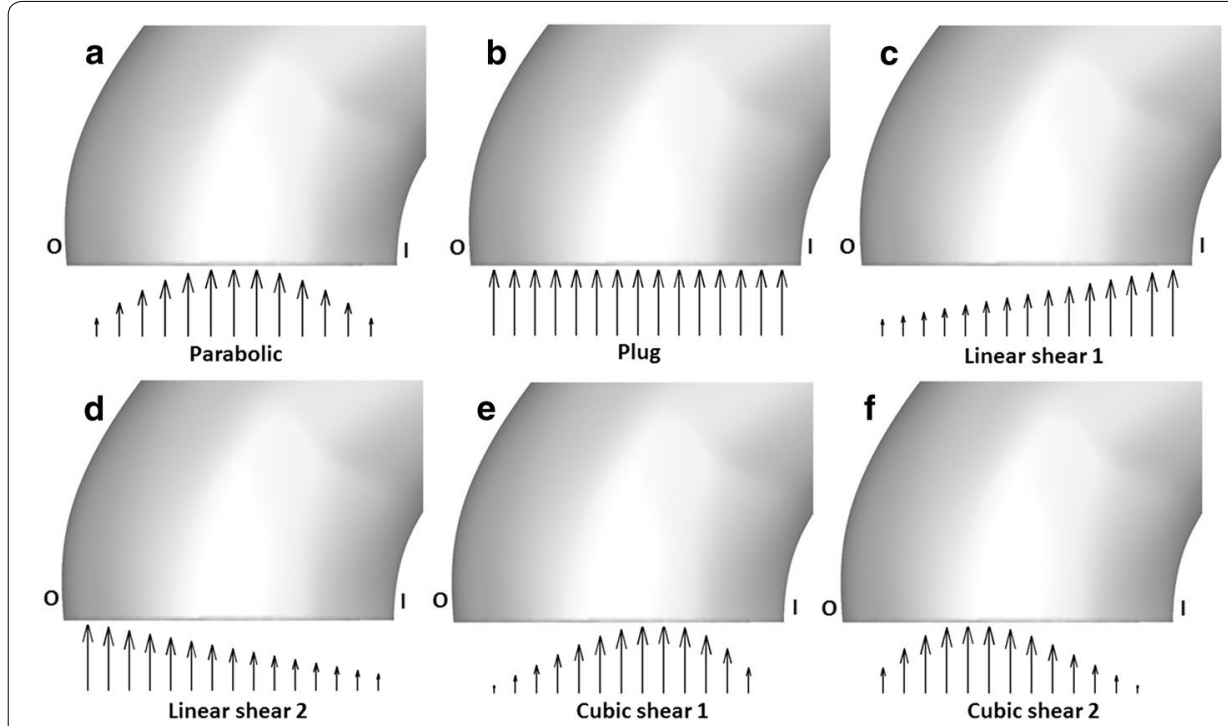

Fig. 3 Select inlet velocity conditions; a parabolic, b plug, c linear shear 1, d linear shear 2, e cubic shear 1, f cubic shear 2 ; I' and ' $O$ 'indicate the inner and outer curve of the aortic arch, respectively

for the aorta due to the complex in vivo upstream conditions caused by the beating heart and the aortic valve. In the current study, the secondary flow specified by Eqs. 2 and 3 was selected not because it accurately represented flow in an in vivo aorta, but because it aided evaluation of the effect on the flow of an arbitrary secondary flow of reasonable strength and shape [71-74]. The effect of secondary flow was studied on the parabolic primary velocity profile since it is the most commonly assumed primary velocity profile shape in cardiovascular simulations.

$$
\begin{aligned}
& \vec{V}=K(t) \cdot\left[\frac{-\left(y-y_{1}\right)}{\left(r-r_{1}\right)^{2}}+\frac{\left(y-y_{2}\right)}{\left(r-r_{2}\right)^{2}}\right] \cdot \hat{\mathbf{j}} \\
& \vec{W}=K(t) \cdot\left[\frac{\left(x-x_{1}\right)}{\left(r-r_{1}\right)^{2}}-\frac{\left(x-x_{2}\right)}{\left(r-r_{2}\right)^{2}}\right] \cdot \hat{\mathbf{k}}
\end{aligned}
$$

In Eqs. 2 and 3, $\vec{V}$ and $\vec{W}$ are velocity vectors perpendicular to the axial velocity vector, $\vec{U} ;\left(x_{1}, y_{1}\right)$ and $\left(x_{2}, y_{2}\right)$ are the coordinates of the centers of vortices; $r_{1}=\sqrt{x_{1}^{2}+y_{1}^{2}}$ and $r_{2}=\sqrt{x_{2}^{2}+y_{2}^{2}} \cdot \vec{V}$ and $\vec{W}$ were set to $\overrightarrow{0}$ at the vortices' centers $(<15 \%$ of vessel radius) to suppress the blowup of velocity components. $K(t)$ was chosen to ensure that the mean secondary flow speed was $24 \%$ of the mean primary flow speed as reported in [70].

\section{Outlet sensitivity studies}

In the second part of this study, we examined the sensitivity of the flow to the choice of outlet boundary conditions, focusing on those most commonly assumed: the outflow condition and the three-element (RCR) and two-element (RC) Windkessel 


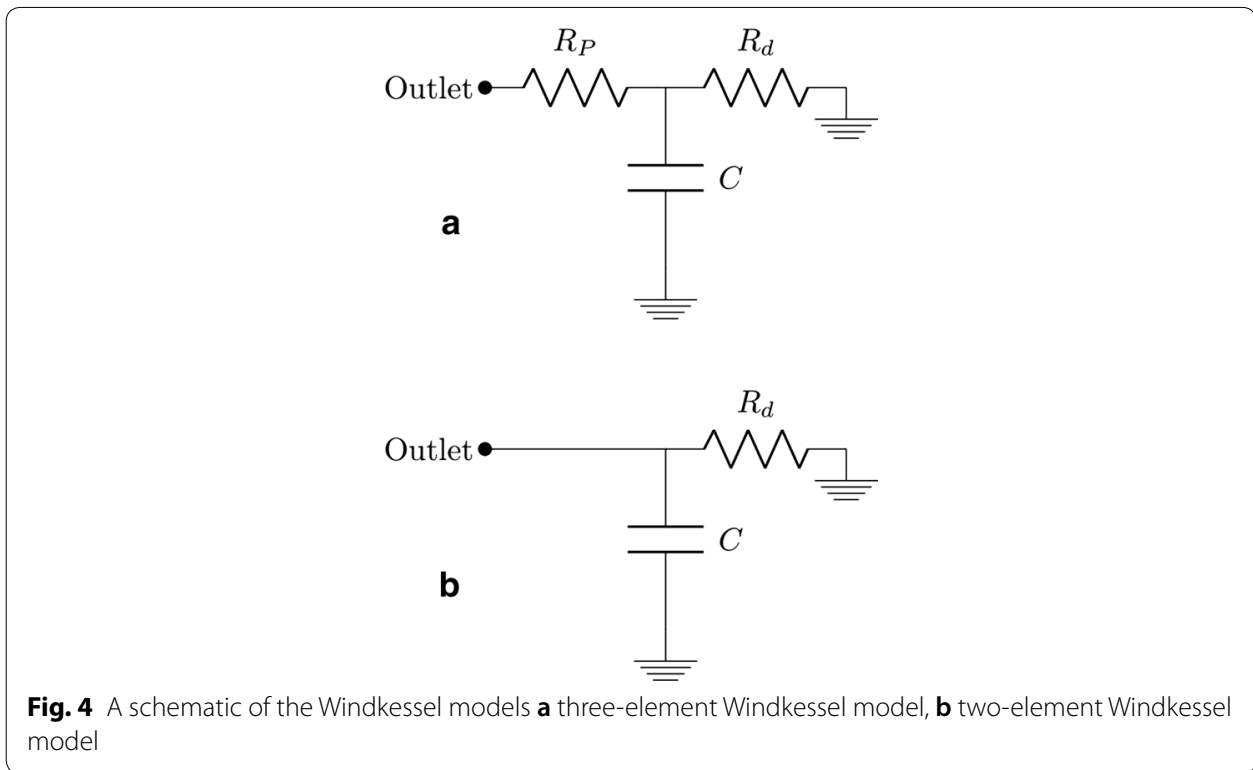

models [75-77]. For these simulations, a parabolic inlet velocity condition was prescribed and there was no secondary flow at the inlet. The Windkessel model was invented in 1899 [78] and later adapted to model transient outflow boundary conditions in [75]. The three-element Windkessel model is an electric-circuit analogue consisting of a proximal resistance, $R_{p}$ in series with a parallel network of a capacitor, $C$, and a distal resistance, $R_{d}$, as shown in Fig. $4 \mathrm{a}$. The two-element model is identical to the three-element model except for the absence of proximal resistance, as shown in Fig. 4b. While the proximal resistance models the viscous resistance of the vasculature immediately downstream of the vessel, the distal resistance accounts for the resistance of the capillaries and the venous circulation. The capacitor is representative of the compliance of the downstream vessels. Assuming such an analogue yields us Eq. 4 [ $[75,79,80]$. The outlet pressure was then obtained using an implicit time discretization of Eq. 4 as described in [80].

$$
\frac{\partial p}{\partial t}+\frac{p}{C R_{d}}=\frac{Q}{C}\left(1+\frac{R_{p}}{R_{d}}\right)+R_{p} \frac{\partial Q}{\partial t}
$$

In Eq. 4, $p$ represents the outlet pressure, and $Q$ represents the flow rate through the vessel. Typically resistance and capacitance parameters for the Windkessel model are tuned to match the outlet flowrate from the in vivo model. However, since flowrates through the outlets were unavailable for this particular patient, these parameters were adapted from a similar aorta model [77]. Table 2 lists resistance and capacitance values used for the various daughter vessels.

For all simulations, flow was assumed to be laminar since the Reynolds number, $\mathbf{R e}_{D}$ based on the inlet aortic diameter, $D$ was about 1700 at peak systole. The simulations were performed until the fifth cardiac cycle. Wall shear stress (WSS), pressure, and vorticity contours were examined from the fifth cardiac cycle. The centerline of the model was computed and data slices perpendicular to the centerline were extracted 
Table 2 Parameters for the Windkessel outlet boundary conditions, adapted from [77]

\begin{tabular}{llll}
\hline Vessel & $\boldsymbol{R}_{\boldsymbol{p}}$ (dynes $\mathbf{~} / \mathbf{c m}^{\mathbf{5}}$ ) & $\mathbf{C}\left(\mathbf{c m}^{\mathbf{5}} \mathbf{\text { dynes}}\right)$ & $\boldsymbol{R}_{\boldsymbol{d}}$ (dynes $\mathbf{s} / \mathbf{c m}^{\mathbf{5}}$ ) \\
\hline Right common carotid & 1180 & $7.70 \mathrm{E}-5$ & 18,400 \\
Right subclavian & 1040 & $8.74 \mathrm{E}-5$ & 16,300 \\
Left common carotid & 1180 & $7.70 \mathrm{E}-5$ & 18,400 \\
Left subclavian & 970 & $9.34 \mathrm{E}-5$ & 15,200 \\
Descending aorta & 188 & $4.82 \mathrm{E}-4$ & 2950
\end{tabular}

Note $R_{p}$ was needed only for the three-element outlet condition, but $C$ and $R_{d}$ were used for both the three- and twoelement conditions

at streamwise coordinates that were multiples of the aortic root diameter, $D$. Timeaveraged wall shear stress (TAWSS) and other time-averaged flow quantities were also computed by averaging over the fifth cardiac cycle. Results comparing the various inlet and outlet boundary conditions are presented in the following sections.

\section{Results and discussion}

\section{Effect of the shape of the inlet axial velocity profile}

This subsection discusses the influence of the axial velocity profile shape on the solution. These flows had no secondary flow at the inlet.

Data slices perpendicular to the centerline of the model were extracted at various locations along the aorta. Figure 5 shows data at streamwise coordinates of $0.5 D$ and $1 D$, where ' $D$ ' is the diameter of the aorta's inlet. Axial velocity magnitudes are depicted by contours. In-plane velocities are represented by the vectors in Fig. 5 . Surfaces closer to the inner and the outer arch are denoted by the letters ' $\mathrm{I}$ ' and ' $\mathrm{O}$ ' respectively. The effect of inlet boundary conditions is more pronounced closer to

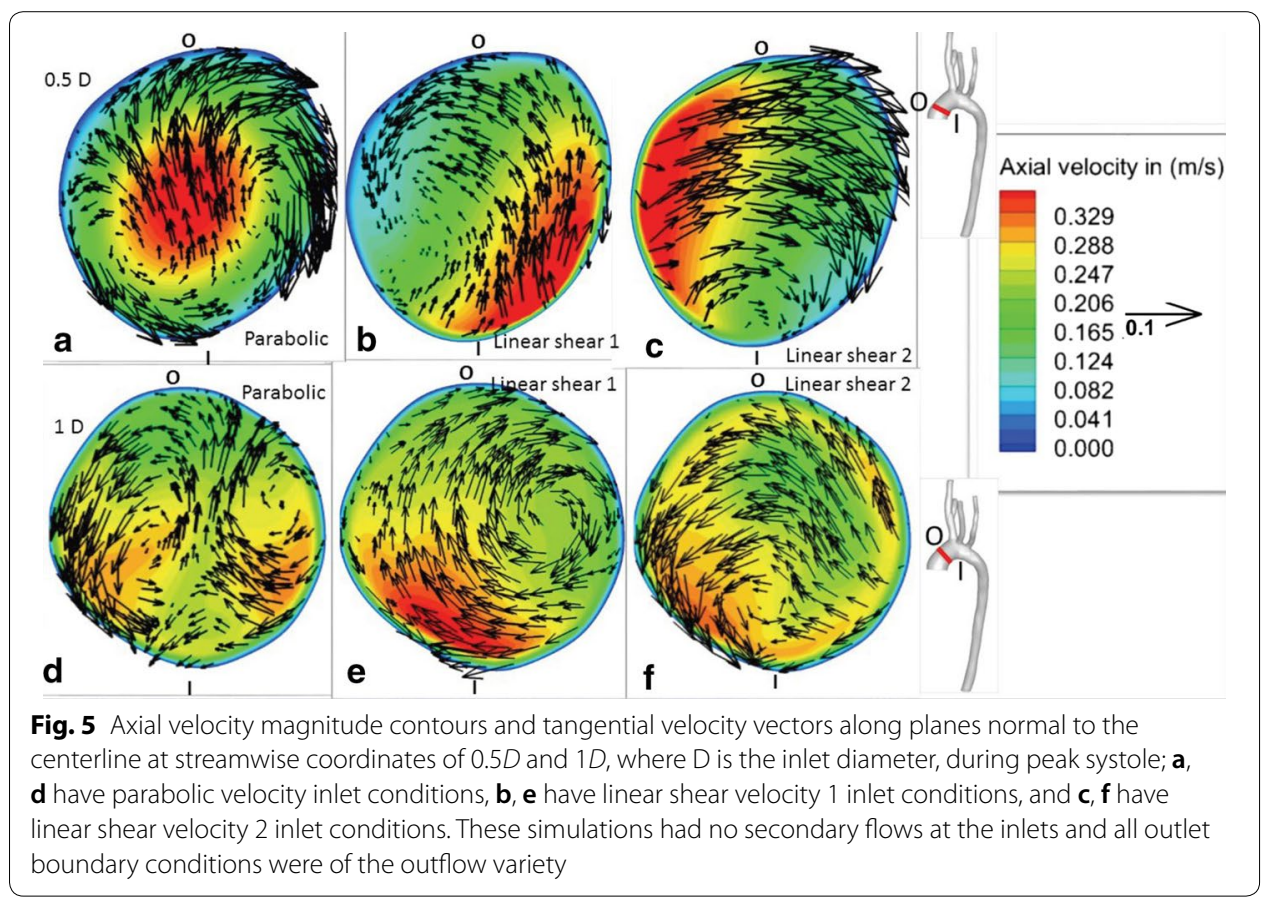


the inlet of the vessel. For instance, the peak in axial velocity is approximately at the center of the cross-section for the parabolic inlet boundary condition, as shown in Fig. 5a. Similarly, the contours in Fig. 5b, c show marked similarities to their respective inlet conditions, linear shear flows 1 and 2. Owing to inertia, flow inside the curved vessel gets pushed towards the outer side of the arch, labeled 'O'. This effect is apparent in the in-plane velocity vectors of the parabolic velocity inlet cross section in Fig. 5a. The counter-rotating vortex (CRV) pair, formed because of the aforesaid effect $[81,82]$, is retained at a streamwise position of $1 D$ for the parabolic inlet boundary condition. In addition to the CRV pair, there is a smaller vortex closer to the inner arch, 'I', for the parabolic inlet boundary condition. A counterclockwise rotating vortex is present in the flow with the linear shear 1 inlet condition. However, the linear shear 2 inlet has a clockwise rotating vortex, observed in Fig. 5c. For linear shear flow inlet boundary conditions, there is a change in the direction of rotation of the tangential velocity vectors with increasing streamwise coordinate. This effect can be observed by comparing Fig. 5b, e for the linear shear 1 inlet condition. A similar trend is also noticeable in Fig. $5 \mathrm{c}, \mathrm{f}$ for the linear shear 2 inlet boundary condition. It is also notable that both the primary and the secondary in-plane flows look considerably different for the three boundary conditions illustrated in Fig. 5, but in all three cases, secondary flows are only a small percentage of the total flow velocity.

Figure 6 shows data slices at streamwise distances of $1.75 \mathrm{D}$ and $2.5 \mathrm{D}$ from the inlet, where $D$ is the inlet diameter, during peak systole. At these cross-sections, all boundary conditions shown yielded a clockwise-rotating secondary flow. Branching vessels have been shown to have a considerable effect on the secondary flow [40] so it is possible this was caused by the branching daughter vessels and the effect of the curvature of the vessel $[40,83,84]$. The velocity of the streamwise flow is skewed towards the inner wall of the vessel. This result agrees well with various other studies such as [40,

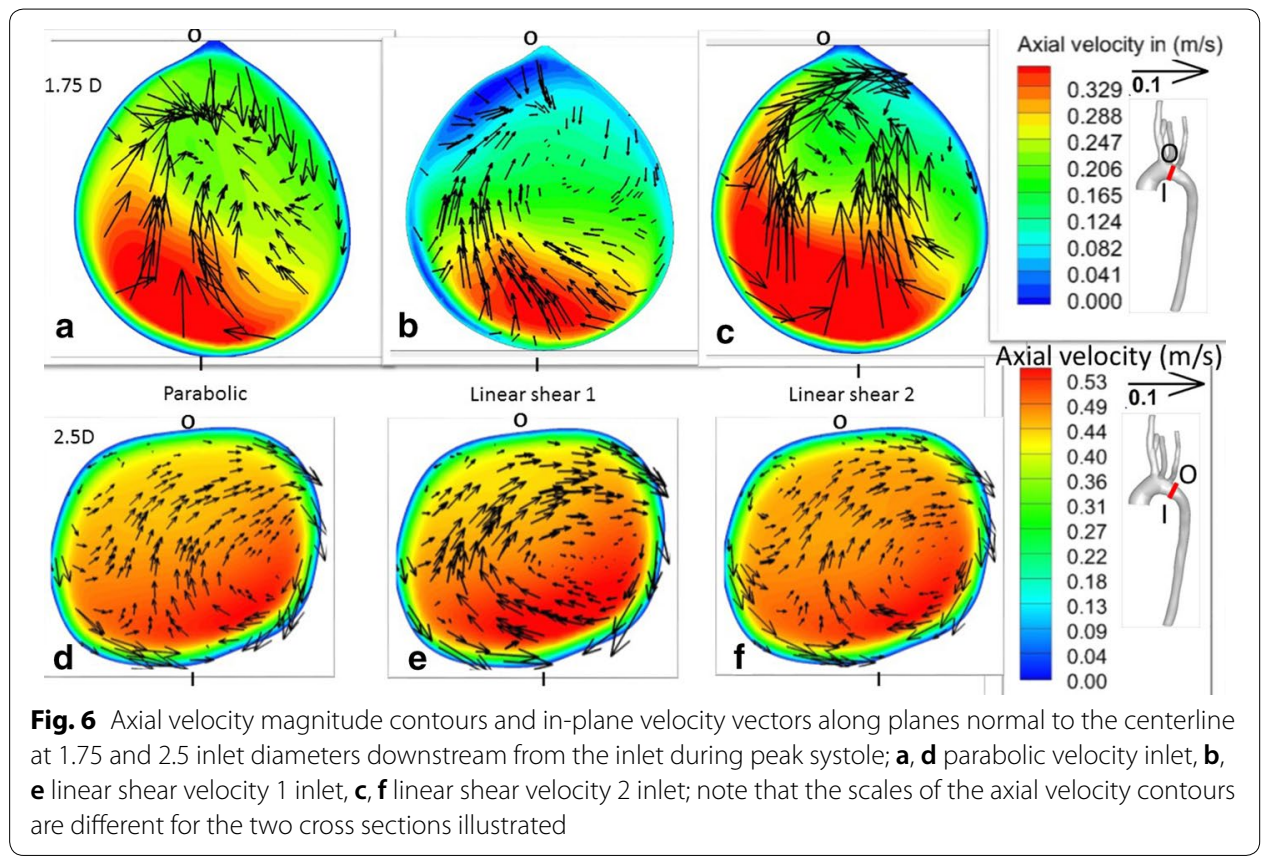


85-88], which have observed reversed and skewed flow along the inner wall of the vessel. Although a direct validation of our simulation cannot be performed due to lack of availability of patient velocity data, the qualitative features from our simulations match well with previous aortic flow studies as indicated above.

There are a few minor differences between the three cases shown in Fig. 6, such as the shape of the peak in axial velocity contours and the direction of vectors in the secondary flow, especially at $1.75 \mathrm{D}$. The differences in axial flow may be caused by a combination of the varying inlet velocity profiles and distortions to the secondary flow caused by the vessel's curvature.

$$
N R M S D=\frac{\sqrt{\frac{\sum_{i=1}^{n}\left(\left(\vec{u}_{\text {parabolic }}\right)_{i}-\left(\vec{U}_{\text {inlet condition }}\right)_{i}\right)^{2}}{n}}}{\left(\left(\vec{U}_{\text {parabolic }}\right)_{i}\right)}
$$

Figure 7 quantifies differences between various inlet boundary conditions and the parabolic inlet velocity boundary condition using normalized root-mean-square deviation (NRMSD) of axial velocity magnitude as described in Eq. 5, integrated over cross-sectional slices at the coordinates indicated. NRMSD generally decreases with increasing streamwise coordinate, although there is a slight increase at $1.75 D$. It is notable that NRMSD is within 0.03 at $2.5 \mathrm{D}$ for every inlet boundary condition examined. This is more than an order of magnitude smaller than its value at the inlet for most boundary conditions.

Figure 8 compares surface pressure and wall shear stress contours for two representative inlet velocity profiles: parabolic and linear shear 1 . The two cases are very similar except for minor differences close to the inlet of the vessel. This was also typical for other inlet velocity profile cases not shown in the figure.

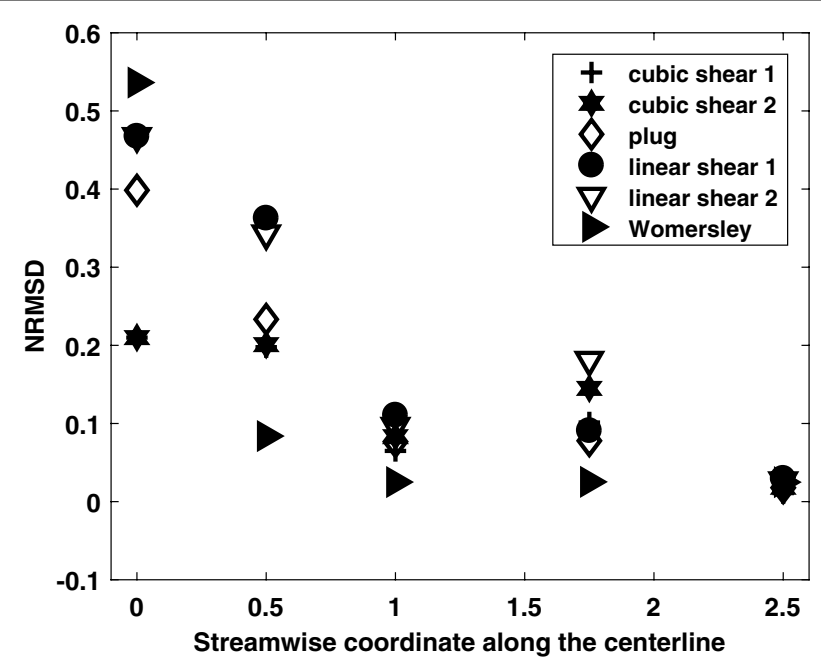

Fig. 7 Normalized root-mean-square deviation (NRMSD) of axial velocity magnitude compared with parabolic inlet boundary conditions at various locations along the streamwise coordinate during peak systole; the streamwise coordinate is measure $d$ in multiples of $D$, the vessel's inlet diameter 


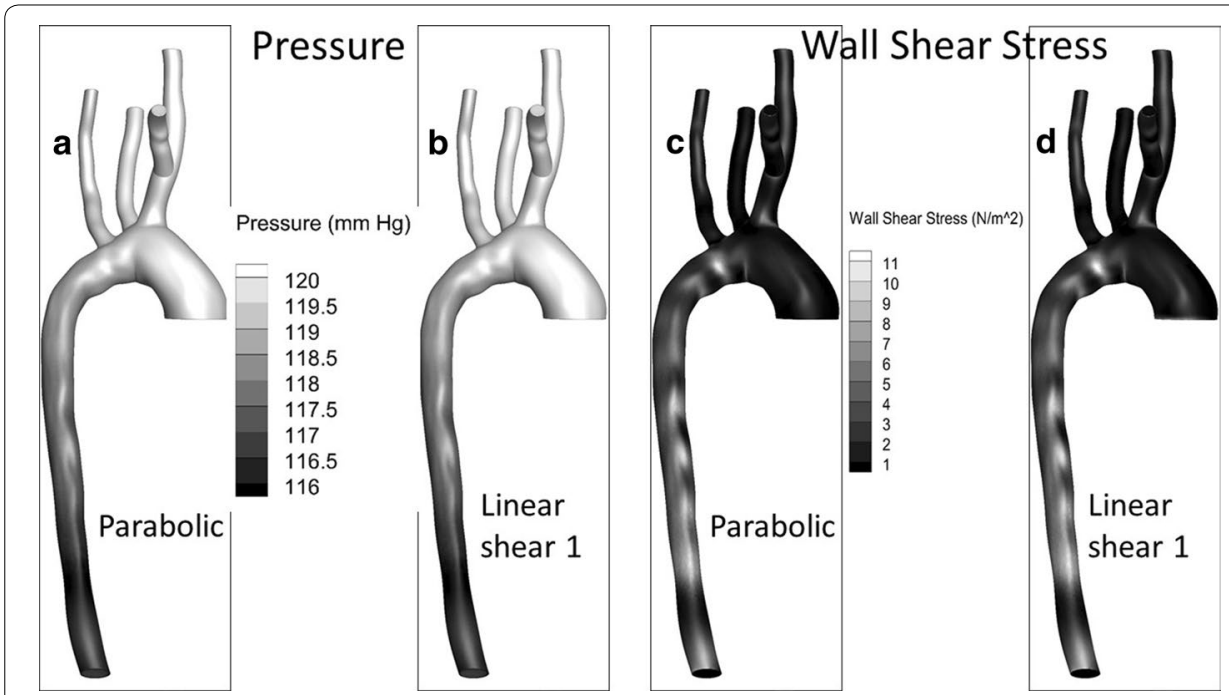

Fig. 8 Pressure and wall shear stress (WSS) contours along the wall of the vessel during peak systole; a, c parabolic inlet condition, $\mathbf{b}, \mathbf{d}$ linear shear 1 inlet condition

Integrated wall shear stress (WSS)

$$
=\left|\frac{100 \cdot \int_{\text {wall }}\left(\tau_{w}\right)_{\text {inlet condition }}-\left(\tau_{w}\right)_{\text {parabolic }} d A}{\int_{\text {wall }}\left(\tau_{w}\right)_{\text {parabolic }} d A}\right|
$$

Time averaged wall shear stress (TAWSS )

$$
=\left|\frac{100 \cdot \int_{\text {cardiac cycle }} \int_{\text {wall }}\left(\tau_{w}\right)_{\text {inlet condition }}-\left(\tau_{w}\right)_{\text {parabolic }} d A \cdot d t}{\int_{\text {cardiac cycle }} \int_{\text {wall }}\left(\tau_{w}\right)_{\text {parabolic }} d A \cdot d t}\right|
$$

Table 3 shows differences between integrated wall shear stress of flows with different inlet conditions compared with the parabolic inlet condition, calculated using Eqs. 6 and 7. The spatial integrals in the aforementioned equations were computed following $\left(A N S Y S^{\circledR}\right.$ Academic Research [Fluent], release 16.2, 20.3, Surface Integration, ANSYS, Inc.). Temporally, the integrals were calculated using a composite trapezoidal rule. The

Table 3 Differences in wall shear stress magnitudes compared with the parabolic inlet velocity boundary condition case as defined in Eqs. 6 and 7

\begin{tabular}{lllll}
\hline $\begin{array}{l}\text { Velocity boundary } \\
\text { condition }\end{array}$ & $\begin{array}{l}\text { Differences in } \\
\text { TAWSS (\%) }\end{array}$ & $\begin{array}{l}\text { Differences in } \\
\text { WSS } \\
\text { during peak systole } \\
(\%)\end{array}$ & $\begin{array}{l}\text { Differences in } \\
\text { TAWSS up to 1D (\%) }\end{array}$ & $\begin{array}{l}\text { Differences in } \\
\text { WSS up to 1D } \\
\text { during peak } \\
\text { systole (\%) }\end{array}$ \\
\hline Plug & 8.72 & 15.69 & 7.21 & 31.48 \\
Womersley & 0.86 & 6.20 & 6.84 & 17.30 \\
Linear shear flow 1 & 8.09 & 11.21 & 18.50 & 32.53 \\
Linear shear flow 2 & 0.99 & 6.42 & 1.47 & 17.24 \\
Cubic shear flow 1 & 5.08 & 0.63 & 12.73 & 2.67 \\
Cubic shear flow 2 & 1.87 & 1.83 & 4.16 & 5.48
\end{tabular}


table contains comparisons for integrated wall shear stress at peak systole (Eq. 6) and time-averaged wall shear stress over a cardiac cycle (Eq. 7). Both of these parameters are integrated over the entire simulation domain. These differences are also quantified locally across the vessel wall up to $1 D$ from the inlet. Linear shear flow 1 and plug flow exhibit the largest differences integrated over the entire domain, about $8 \%$ in time-averaged wall shear stress. During peak systole these numbers are as high as $15 \%$ for plug flow. However, in the first $1 D$ from the inlet, linear shear flow 1 has the largest local variations, about $18 \%$ in time-averaged wall shear stress and about $33 \%$ in integrated wall shear stress during peak systole. It is also notable that the parabolic inlet condition has the lowest integrated wall shear stress and time-averaged wall shear stress among the inlet conditions examined.

\section{Effect of adding secondary flow to the inlet}

In this subsection, the effect of adding secondary flow to a parabolic axial inlet velocity profile is discussed. Only the parabolic axial flow is considered since it is the most commonly assumed inlet velocity profile shape in cardiovascular simulations.

Table 4 illustrates the variations in wall shear stress magnitudes between parabolic inlet flows with and without secondary flow at the inlet. Wall shear stress magnitude variations are significantly higher during diastole. Wall shear stress magnitudes vary the most near the inlet, but this phenomenon is also observed when wall shear stress is integrated over the entire domain.

The magnitude of these differences must be interpreted in the context of other uncertainties in cardiovascular flow simulation. For example, in an image-based coronary arterial model examined by [25, 26], different models of blood rheology accounted for about $8 \%$ variability in the solution, the effect of secondary inlet flow yielded $13 \%$ variability, and geometric uncertainties resulted in $47 \%$ variability in wall shear stress. It is notable that they generated secondary flow using an extension to their model with added curvature and helical pitch. Another study, [83], examined the effect of curvature and inlet velocity profile on a right coronary artery model. They concluded that inlet velocity profile had little effect on the flow compared with the effect of changing the curvature of the model. From our study, it is evident that the effect of changing the shape of the primary flow inlet velocity profile is not felt significantly beyond $1.75 D$, with $D$ being the aortic root diameter. However, upstream of $1 D$, the shape of the axial flow can lead to as much as $18 \%$ variability in terms of timeaveraged wall shear stress. Adding secondary flow on top of parabolic axial flow also results in significant variability in wall shear stress upstream of $1 D$, as high as $26 \%$ during diastole. Consequently, if accurate temporal modeling closer to the inlet and

Table 4 Differences in wall shear stress magnitudes of the parabolic inlet velocity boundary condition cases with and without secondary flow

\begin{tabular}{llll}
\hline Integration domain & $\begin{array}{l}\text { Differences } \\
\text { in TAWSS (\%) }\end{array}$ & $\begin{array}{l}\text { Differences in } \\
\text { WSS during peak } \\
\text { systole (\%) }\end{array}$ & $\begin{array}{l}\text { Differences in } \\
\text { WSS } \\
\text { during diastole }\end{array}$ \\
\hline Entire wall surface & 3.58 & 0.19 & 5.35 \\
Wall surface up to 1D & 7.74 & 1.50 & 26.56 \\
\hline
\end{tabular}

The secondary flow used is defined in Eqs. 2, 3 
Table 5 Differences in wall shear stress magnitudes between the three-element Windkessel (RCR), the two-element Windkessel (RC), and the prescribed percentage flow rate outlet (outflow) boundary conditions

\begin{tabular}{llllc}
\hline WSS comparision & $\begin{array}{l}\text { Differences in } \\
\text { TAWSS (\%) } \\
\text { up to 1D (\%) }\end{array}$ & $\begin{array}{l}\text { Differences in } \\
\text { WSS up to 1D (\%) } \\
\text { during peak systole }\end{array}$ & $\begin{array}{l}\text { Differences in } \\
\text { TAWSS (\%) }\end{array}$ & $\begin{array}{l}\text { Differences in } \\
\text { WSS (\%) } \\
\text { during peak } \\
\text { systole }\end{array}$ \\
\hline RCR and outflow & 0.3571 & 2.8515 & 18.2248 & 14.2861 \\
RC and outflow & 0.3544 & 2.8528 & 18.2758 & 14.3076 \\
RCR and RC & 0.0027 & 0.0013 & 0.0431 & 0.0250 \\
\hline
\end{tabular}

All cases here had a parabolic inlet velocity profile and no secondary flow at the inlet

the aortic arch is desired, our results emphasize the need to model patient-specific inlet velocity conditions including secondary flow.

\section{Effect of outlet boundary conditions}

Table 5 illustrates the differences in wall shear stress magnitude between the threeelement Windkessel model, the two-element Windkessel model, and the prescribed percentage outflow boundary conditions. All three of these cases had identical parabolic inlet axial velocity conditions and no secondary flow at the inlet. The data show no significant difference in wall shear stress between the two-element Windkessel and the three-element Windkessel conditions. However, the two-element and the threeelement models vary as much as about $18 \%$ from the case with an outflow boundary condition. Comparing these results with the magnitude of variations from other factors suggests that outlet boundary conditions are a significant contributor to uncertainty in the solution.

Figure 9 shows the differences between the Windkessel boundary conditions and the outflow condition using normalized root-mean-square deviation (NRMSD) of axial velocity magnitude as described in Eq. 5, integrated over cross-sectional slices at the coordinates indicated. A general increase in NRMSD is observed with increasing streamwise coordinate, although there is a slight decrease at $4.5 \mathrm{D}$ relative to that observed at 3.5D. Furthermore, variation in NRMSD beyond $3.5 \mathrm{D}$ is constant within $2.5 \%$ for both the Windkessel boundary conditions examined. The fact that NRMSD is highest near the outlet is expected when comparing cases that vary outlet conditions. However, it is notable that whereas NRMSD decayed nearly to zero for all inlet conditions by 2.5 diameters from the inlet, NRMSD remained high more than 5 diameters proximal to the outlet. This suggests that the choice of outlet condition has a noticeable effect on a larger percentage of the solution domain than the choice of inlet condition.

\section{Conclusions and summary}

This work investigated the variation introduced into a simulation of aortic blood flow by choice of inlet and outlet boundary conditions.

Inlet plug flow, parabolic flow, linear shear flows, skewed cubic flows, and Womersley flow were simulated and the resulting flow solutions were compared to study the 


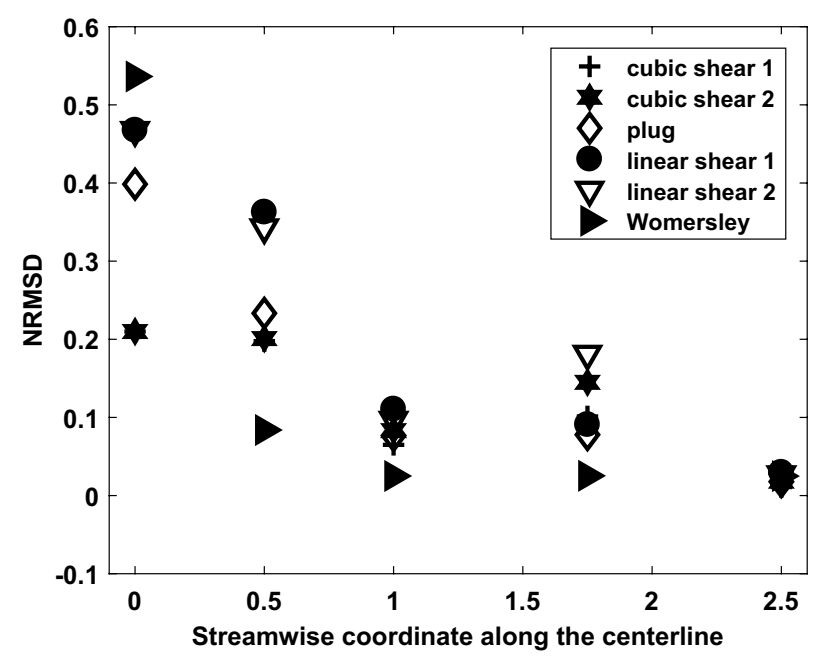

Fig. 9 Normalized root-mean-square deviation (NRMSD) of axial velocity magnitude compared with outflow outlet boundary condition at various locations along the streamwise coordinate during peak systole; the streamwise coordinate is measured in multiples of $D$, the vessel's inlet diameter. These simulations had parabolic inlet boundary condition with no secondary flow

effect of inlet conditions. Parabolic flow with and without secondary flow at the inlet was also studied. All other parameters were identical among these simulations. While the parabolic inlet condition without secondary flow has the lowest time-averaged wall shear stress, linear shear flow and plug flow have the highest time-averaged wall shear stress, about $8 \%$ higher than parabolic inlet condition without secondary flow. The axial and in-plane velocities for the different flow solutions are considerably different across data slices extracted at $0.5 D$ and $1 D$ from the inlet, where $D$ is the inlet diameter. Data slices at $1.75 D$ and $2.5 D$ are qualitatively similar but there are minor differences between secondary flows at $1.75 D$. Normalized root-mean-square deviation (NRMSD) evaluated between the parabolic inlet condition without secondary flow and other axial velocity boundary conditions generally decreases along the streamwise coordinate and is less than 0.03 at $2.5 D$ for all cases. These statistics show that the effect of inlet conditions becomes less pronounced as the streamwise coordinate increases. Adding secondary inlet flow to parabolic axial flow results in a slight variation of about $4 \%$ in terms of the time-averaged wall shear stress. However, between the inlet and a streamwise coordinate of $1 D$, there are larger differences. This is especially noticeable during diastole when shear stress magnitude differences integrated up to 1D are as high as $26 \%$.

Outlet conditions prescribing a zero-diffusion flux with specified mass flow rate $\left(A N S Y S^{\circledR}\right.$ Academic Research [Fluent], release 16.2, outflow boundary conditions, ANSYS, Inc.), two-element Windkessel, and the three-element Windkessel conditions were investigated. Both the two-element and the three-element Windkessel models don't vary much near the inlet as seen from the time-averaged wall shear stress variations. For instance, both the two-element and the three-element models differ from the outflow boundary condition by 0.3544 and $0.3571 \%$ respectively in terms of time-averaged wall shear stress integrated up to $1 D$. However, in terms of time-averaged wall shear stress integrated throughout the model, they differ from the outflow boundary condition by 
as much as about $18 \%$. Normalized root-mean-square deviation (NRMSD) evaluated between the outflow boundary condition and the Windkessel models generally increases along the streamwise coordinate. However, beyond 3.5D NRMSD varies by less than $2.5 \%$ along the streamwise coordinate. These statistics indicate that NRMSD remains constant for more than 5 diameters proximal to the outlet and that the effect of outlet conditions are more pronounced as the streamwise coordinate increases.

Based on the current results along with other studies on the subject $[70,89,90]$, it is reasonable to conclude that inlet conditions, including both primary and secondary velocity profile shape, significantly affect the solution up to about two inlet diameters distal to the inlet. Similarly, the type of outlet condition chosen affects the solution significantly up to five inlet diameters proximal to the outlet. This suggests that the outlet boundary conditions influence a larger percent of the solution domain. The amount of variation observed between the various flow cases in this study can be interpreted as a lower bound on the error that can be expected in aortic flow simulations that do not use patient-specific boundary conditions. Although this study is limited to one healthy model, the underlying mechanisms of flow over the curvature of the vessel and the effect of branches would likely render qualitatively similar results in other subject-specific models. Nevertheless, studying more subject-specific models along with corresponding physiologically realistic inlet velocity boundary conditions to verify our conclusions is of interest for future work.

\section{List of symbols}

Symbols

D: diameter of aorta at the inlet; $\vec{U}$ : axial velocity vector.

Greek letters

$\tau$ : shear stress.

Non-dimensional numbers

Re: Reynolds number.

Subscripts or superscripts

w: wall.

Acronyms and abbreviations

NRMSD: normalized root-mean-square deviation; WSS: wall shear stress; TAWSS: time-averaged wall shear stress.

Authors' contributions

EK designed the study and evaluation procedures. SM worked on implementing the study; preparing the model, simulating, and post processing the data. SM wrote this manuscript. EK contributed in reviewing and revising it. Both authors read and approved the final manuscript.

\section{Authors' information}

Sudharsan Madhavan received his bachelor's degree in mechanical engineering from Indian Institute of Information Technology Design \\& Manufacturing Kancheepuram, India and his masters in applied mathematics from University of Washington, Seattle, USA. He is currently a doctoral candidate at Tufts university, Medford, USA, working on cardiovascular fluid dynamics.

Erica M. Cherry Kemmerling holds a B.S. in physics and an M.S. and Ph.D. in mechanical engineering from Stanford University. She is currently an assistant professor of mechanical engineering at Tufts University. Her research focuses on fluid flow and mass transport in the human body with an emphasis on the circulatory system.

Acknowledgements

The authors would like to acknowledge Stanford Cardiovascular Biomechanics Computation Lab for letting us use their subject-specific model.

Competing interests

The authors declare that they have no competing interests.

Consent for publication

Not applicable. 


\section{Data availability}

Please contact sudharsan.madhavan@tufts.edu for data requests.

Ethics approval and consent to participate

Not applicable.

\section{Publisher's Note}

Springer Nature remains neutral with regard to jurisdictional claims in published maps and institutional affiliations.

Received: 22 June 2017 Accepted: 10 May 2018

Published online: 30 May 2018

\section{References}

1. Amman HM, Tesfatsion L, Kendrick DA, Judd KL, Rust J. Handbook of computational economics, vol. 2. Amsterdam: Elsevier; 1996

2. Wong KK, Kelso RM, Worthley S, Sanders P, Mazumdar J, Abbott D. Medical imaging and processing methods for cardiac flow reconstruction. J Mech Med Biol. 2009;9(01):1-20.

3. Wong KK, Kelso RM, Worthley SG, Sanders P, Mazumdar J, Abbott D. Cardiac flow analysis applied to phase contrast magnetic resonance imaging of the heart. Ann Biomed Eng. 2009;37(8):1495-515.

4. Wong KK, Sun Z, Tu J, Worthley SG, Mazumdar J, Abbott D. Medical image diagnostics based on computer-aided flow analysis using magnetic resonance images. Comput Med Imaging Graph. 2012;36(7):527-41.

5. Koo JK, Sohn BS, Hong BW. Segmentation of left ventricle in cardiac MRI via contrast-invariant deformable template. J Med Imaging Health Inform. 2017;7(8):1682-8.

6. Mendis S, Puska P, Norrving B, et al. Global atlas on cardiovascular disease prevention and control. Geneva: World Health Organization; 2011.

7. Naghavi M, Wang H, Lozano R, Davis A, Liang X, Zhou M, et al. Gbd 2013 mortality and causes of death collaborators. global, regional, and national age-sex specific all-cause and cause-specific mortality for 240 causes of death, 1990-2013: a systematic analysis for the global burden of disease study 2013. Lancet. 2015;385(9963):117-71.

8. Hlatky MA, De Bruyne B, Pontone G, Patel MR, Norgaard BL, Byrne RA, Curzen N, Purcell I, Gutberlet M, Rioufol G, et al. Quality-of-life and economic outcomes of assessing fractional flow reserve with computed tomography angiography: platform. J Am Coll Cardiol. 2015:66(21):2315-23.

9. Nørgaard BL, Gaur S, Leipsic J, Ito H, Miyoshi T, Park S-J, Zvaigzne L, Tzemos N, Jensen JM, Hansson N, et al. Influence of coronary calcification on the diagnostic performance of ct angiography derived FFR in coronary artery disease: a substudy of the NXT trial. JACC: Cardiovasc Imaging. 2015;8(9):1045-55.

10. Sundareswaran KS, De Zelicourt D, Pekkan K, Jayaprakash G, Kim D, Whited B, Rossignac J, Fogel MA, Kanter KR, Yoganathan AP. Anatomically realistic patient-specific surgical planning of complex congenital heart defects using MRI and CFD. In: 2007 29th Annual International Conference of the IEEE Engineering in Medicine and Biology Society. New York: IEEE; 2007. p. 202-5.

11. Marsden AL. Optimization in cardiovascular modeling. Annu Rev Fluid Mech. 2014;46:519-46.

12. Dumont K, Vierendeels J, Kaminsky R, Van Nooten G, Verdonck P, Bluestein D. Comparison of the hemodynamic and thrombogenic performance of two bileaflet mechanical heart valves using a CFD/FSI model. J Biomech Eng. 2007;129(4):558-65.

13. Dur O, Coskun ST, Coskun KO, Frakes D, Kara LB, Pekkan K. Computer-aided patient-specific coronary artery graft design improvements using CFD coupled shape optimizer. Cardiovasc Eng Technol. 2011;2(1):35-47.

14. Ge L, Leo H-L, Sotiropoulos F, Yoganathan AP. Flow in a mechanical bileaflet heart valve at laminar and near-peak systole flow rates: CFD simulations and experiments. J Biomech Eng. 2005;127(5):782-97.

15. King M, Corden J, David T, Fisher J. A three-dimensional, time-dependent analysis of flow through a bileaflet mechanical heart valve: comparison of experimental and numerical results. J Biomech. 1996;29(5):609-18.

16. Mihalef V, Ionasec RI, Sharma P, Georgescu B, Voigt I, Suehling M, Comaniciu D. Patient-specific modelling of whole heart anatomy, dynamics and haemodynamics from four-dimensional cardiac ct images. Interface Focus. 2011;1(3):286-96

17. Shi Y, Zhao Y, Yeo T, Hwang N. Numerical simulation of opening process in a bileaflet mechanical heart valve under pulsatile flow condition. J Heart Valve Dis. 2003;12(2):245-55.

18. Yoganathan AP, Chandran K, Sotiropoulos F. Flow in prosthetic heart valves: state-of-the-art and future directions. Ann Biomed Eng. 2005:33(12):1689-94.

19. Liu X, Gao Z, Xiong H, Ghista D, Ren L, Zhang H, Wu W, Huang W, Hau WK. Three-dimensional hemodynamics analysis of the circle of willis in the patient-specific nonintegral arterial structures. Biomech Model Mechanobiol. 2016;15(6):1439-56

20. Valen-Sendstad K, Steinman D. Mind the gap: impact of computational fluid dynamics solution strategy on prediction of intracranial aneurysm hemodynamics and rupture status indicators. Am J Neuroradiol. 2014;35(3):536-43.

21. Valen-Sendstad K, Piccinelli M, Steinman DA. High-resolution computational fluid dynamics detects flow instabilities in the carotid siphon: implications for aneurysm initiation and rupture? J Biomech. 2014;47(12):3210-6.

22. Steinman DA, Hoi Y, Fahy P, Morris L, Walsh MT, Aristokleous N, Anayiotos AS, Papaharilaou Y, Arzani A, Shadden SC, Berg P, Janiga G, Bols J, Segers P, Bressloff NW, Cibis M, Gijsen FH, Cito S, Pallarés J, Browne LD, Costelloe JA, Lynch AG, Degroote J, Vierendeels J, Fu W, Qiao A, Hodis S, Kallmes DF, Kalsi H, Long Q, Kheyfets VO, Finol EA, Kono K, Malek AM, Lauric A, Menon PG, Pekkan K, Esmaily Moghadam M, Marsden AL, Oshima M, Katagiri K, Peiffer V, Mohamied Y, Sherwin SJ, Schaller J, Goubergrits L, Usera G, Mendina M, Valen-Sendstad K, Habets DF, Xiang J, 
Meng H, Yu Y, Karniadakis GE, Shaffer N, Loth F. Variability of computational fluid dynamics solutions for pressure and flow in a giant aneurysm: the ASME 2012 summer bioengineering conference CFD challenge. J Biomech Eng 2013;135(2):021016

23. Pekkan K, De Zélicourt D, Ge L, Sotiropoulos F, Frakes D, Fogel MA, Yoganathan AP. Physics-driven cfd modeling of complex anatomical cardiovascular flowsa tcpc case study. Ann Biomed Eng. 2005;33(3):284-300.

24. Schenkel T, Malve M, Reik M, Markl M, Jung B, Oertel H. Mri-based CFD analysis of flow in a human left ventricle: methodology and application to a healthy heart. Ann Biomed Eng. 2009;37(3):503-15.

25. Moyle KR, Antiga L, Steinman DA. Inlet conditions for image-based cfd models of the carotid bifurcation: is it reasonable to assume fully developed flow? J Biomech Eng. 2006;128(3):371-9.

26. Lee S-W, Steinman DA. On the relative importance of rheology for image-based cfd models of the carotid bifurcation. J Biomech Eng. 2007;129(2):273-8.

27. Sankaran S, Kim HJ, Choi G, Taylor CA. Uncertainty quantification in coronary blood flow simulations: impact of geometry, boundary conditions and blood viscosity. J Biomech. 2016;49(12):2540-7.

28. Sankaran S, Marsden AL. A stochastic collocation method for uncertainty quantification and propagation in cardiovascular simulations. J Biomech Eng. 2011;133(3):031001.

29. Sankaran S, Grady L, Taylor CA. Impact of geometric uncertainty on hemodynamic simulations using machine learning. Comput Methods Appl Mech Eng. 2015;297:167-90.

30. Liu X, Zhang H, Ren L, Xiong H, Gao Z, Xu P, Huang W, Wu W. Functional assessment of the stenotic carotid artery by CFD-based pressure gradient evaluation. Am J Physiol Heart Circ Physiol. 2016;311(3):645-53.

31. Xiong H, Liu X, Tian X, Pu L, Zhang H, Lu M, Huang W, Zhang YT. A numerical study of the effect of varied blood pressure on the stability of carotid atherosclerotic plaque. Biomed Eng Online. 2014;13(1):152.

32. Wong KK, Thavornpattanapong P, Cheung SC, Tu J. Biomechanical investigation of pulsatile flow in a three-dimensional atherosclerotic carotid bifurcation model. J Mech Med Biol. 2013;13(01):1350001.

33. Liu G, Wu J, Huang W, Wu W, Zhang H, Wong KK, Ghista DN. Numerical simulation of flow in curved coronary arteries with progressive amounts of stenosis using fluid-structure interaction modelling. J Med Imaging Health Inform. 2014;4(4):605-11.

34. Paulsen PK, Hasenkam JM. Three-dimensional visualization of velocity profiles in the ascending aorta in dogs, measured with a hot-film anemometer. J Biomech. 1983;16(3):201-10.

35. Mathison M, Furuse A, Asano K. Doppler analysis of flow velocity profile at the aortic root. J Am Coll Cardiol. 1988;12(4):947-54.

36. Haugen BO, Berg S, Brecke KM, Torp H, Slørdahl SA, Skjærpe T, Samstad SO. Blood flow velocity profiles in the aortic annulus: a 3-dimensional freehand color flow doppler imaging study. J Am Soc Echocardiogr. 2002;15(4):328-33.

37. Gao F, Watanabe M, Matsuzawa T. Stress analysis in a layered aortic arch model under pulsatile blood flow. Biomed Eng Online. 2006;5(1):1.

38. Mori D, Yamaguchi T. Computational fluid dynamics modeling and analysis of the effect of 3-d distortion of the human aortic arch. Comput Methods Biomech Biomed Eng. 2002;5(3):249-60.

39. Tokuda Y, Song M-H, Ueda Y, Usui A, Akita T, Yoneyama S, Maruyama S. Three-dimensional numerical simulation of blood flow in the aortic arch during cardiopulmonary bypass. Eur J Cardiothorac Surg. 2008;33(2):164-7.

40. Shahcheraghi N, Dwyer H, Cheer A, Barakat A, Rutaganira T. Unsteady and three-dimensional simulation of blood flow in the human aortic arch. J Biomech Eng. 2002;124(4):378-87.

41. Pereira V, Brina O, Gonzales AM, Narata A, Bijlenga P, Schaller K, Lovblad K, Ouared R. Evaluation of the influence of inlet boundary conditions on computational fluid dynamics for intracranial aneurysms: a virtual experiment. Biomech. 2013;46(9):1531-9.

42. Womersley JR. Method for the calculation of velocity, rate of flow and viscous drag in arteries when the pressure gradient is known. J Physiol. 1955;127(3):553.

43. Zamir M, Zamir M. The physics of pulsatile flow. Ontario: Springer; 2000.

44. Gundert TJ, Marsden AL, Yang W, LaDisa JF. Optimization of cardiovascular stent design using computational fluid dynamics. J Biomech Eng. 2012;134(1):011002.

45. Alastruey J, Xiao N, Fok H, Schaeffter T, Figueroa CA. On the impact of modelling assumptions in multi-scale, subjectspecific models of aortic haemodynamics. J R Soc Interface. 2016;13(119):20160073.

46. Perktold K, Rappitsch G. Computer simulation of local blood flow and vessel mechanics in a compliant carotid artery bifurcation model. J Biomech. 1995;28(7):845-56

47. Oshima M, Torii R, Kobayashi T, Taniguchi N, Takagi K. Finite element simulation of blood flow in the cerebral artery. Comput Methods Appl Mech Eng. 2001;191(6-7):661-71.

48. Arzani A, Les AS, Dalman RL, Shadden SC. Effect of exercise on patient specific abdominal aortic aneurysm flow topology and mixing. Int J Numer Methods Biomed Eng. 2014;30(2):280-95. https://doi.org/10.1002/cnm.2601.

49. Mukherjee $D$, Shadden SC. Inertial particle dynamics in large artery flows implications for modeling arterial embolisms. J Biomech. 2017;52:155-64. https://doi.org/10.1016/j.jbiomech.2016.12.028.

50. Patankar S. Numerical heat transfer and fluid flow. Boca Raton: CRC press; 1980.

51. Elert G. Density of blood. The physics hypertextbook.

52. Elert G. Viscosity. The physics hypertextbook.

53. Soulis JV, Giannoglou GD, Chatzizisis YS, Farmakis TM, Giannakoulas GA, Parcharidis GE, Louridas GE. Spatial and phasic oscillation of non-newtonian wall shear stress in human left coronary artery bifurcation: an insight to atherogenesis. Coron Artery Dis. 2006;17(4):351-8.

54. Johnston BM, Johnston PR, Corney S, Kilpatrick D. Non-newtonian blood flow in human right coronary arteries: transient simulations. J Biomech. 2006;39(6):1116-28.

55. Katritsis D, Kaiktsis L, Chaniotis A, Pantos J, Efstathopoulos EP, Marmarelis V. Wall shear stress: theoretical considerations and methods of measurement. Prog Cardiovasc Dis. 2007:49(5):307-29.

56. Soulis JV, Lampri OP, Fytanidis DK, Giannoglou GD. Relative residence time and oscillatory shear index of non-Newtonian flow models in aorta. In: 2011 10th International Workshop on Biomedical Engineering. New York: IEEE; 2011. p. $1-4$. 
57. Perktold K, Resch M, Florian H. Pulsatile non-Newtonian flow characteristics in a three-dimensional human carotid bifurcation model. J Biomech Eng. 1991;113(4):464-75.

58. Anor T, Grinberg L, Baek H, Madsen JR, Jayaraman MV, Karniadakis GE. Modeling of blood flow in arterial trees. Wiley Interdiscip Rev Syst Biol Med. 2010;2(5):612-23.

59. Torii R, Wood NB, Hadjiloizou N, Dowsey AW, Wright AR, Hughes AD, Davies J, Francis DP, Mayet J, Yang GZ, et al. Fluid-structure interaction analysis of a patient-specific right coronary artery with physiological velocity and pressure waveforms. Commun Numer Methods Eng. 2009;25(5):565-80.

60. Dempere-Marco L, Oubel E, Castro M, Putman C, Frangi A, Cebral J. CFD analysis incorporating the influence of wall motion: application to intracranial aneurysms. In: International Conference on Medical Image Computing and Computer-Assisted Intervention. Berlin: Springer; 2006. p. 438-45.

61. Santamarina A, Weydahl E, Siegel JM Jr, Moore JE Jr. Computational analysis of flow in a curved tube model of the coronary arteries: effects of time-varying curvature. Ann Biomed Eng. 1998;26(6):944-54.

62. Tse KM, Chiu P, Lee HP, Ho P. Investigation of hemodynamics in the development of dissecting aneurysm within patient-specific dissecting aneurismal aortas using computational fluid dynamics (CFD) simulations. J Biomech. 2011:44(5):827-36.

63. Svensson J, Gårdhagen R, Heiberg E, Ebbers T, Loyd D, Länne T, Karlsson M. Feasibility of patient specific aortic blood flow CFD simulation. In: International conference on medical image computing and computer-assisted intervention. Berlin: Springer; 2006. p. 257-63.

64. Valverde I, Staicu C, Grotenhuis H, Marzo A, Rhode K, Shi Y, Brown AG, Tzifa A, Hussain T, Greil G, Lawford P, Razavi R, Hose R, Beerbaum P. Predicting hemodynamics in native and residual coarctation: preliminary results of a rigid-wall computational-fluid-dynamics model (RW-CFD) validated against clinically invasive pressure measures at rest and during pharmacological stress. J Cardiovasc Magn Reson. 2011;13(1):1-4. https://doi. org/10.1186/1532-429X-13-S1-P49.

65. Liu J, Qian Y, Itatani K, Miyakoshi T, Murakami A, Ono M, Shiurba R, Miyaji K, Umezu M. An approach of computational hemodynamics for cardiovascular flow simulation. In: ASME-JSME-KSME 2011 joint fluids engineering conference. New York: American Society of Mechanical Engineers; 2011. p. 1449-56.

66. Ding J, Chai L, Liu Y. Hemodynamic based cardiovascular surgical planning system. In: 2010 3rd international conference on biomedical engineering and informatics, vol. 1. New York: IEEE; 2010. p. 290-3.

67. Mills C, Gabe I, Gault J, Mason D, Ross J, Braunwald E, Shillingford J. Pressure-flow relationships and vascular impedance in man. Cardiovasc Res. 1970;4(4):405-17.

68. Fuster V, Walsh RA, Harrington RA. Hurst's the heart. New York: Health Professions Division, McGraw-Hill; 2011.

69. Peterson SD. On the effect of perturbations on idealized flow in model. Ph.D. thesis, Purdue University West Lafayette; 2006.

70. Morbiducci U, Ponzini R, Gallo D, Bignardi C, Rizzo G. Inflow boundary conditions for image-based computational hemodynamics: impact of idealized versus measured velocity profiles in the human aorta. J Biomech. 2013;46(1):102-9.

71. Kilner PJ, Yang GZ, Mohiaddin RH, Firmin DN, Longmore DB. Helical and retrograde secondary flow patterns in the aortic arch studied by three-directional magnetic resonance velocity mapping. Circulation. 1993;88(5):2235-47.

72. Frydrychowicz A, Berger A, Del Rio AM, Russe MF, Bock J, Harloff A, Markl M. Interdependencies of aortic arch secondary flow patterns, geometry, and age analysed by 4-dimensional phase contrast magnetic resonance imaging at 3 tesla. Eur Radiol. 2012;22(5):1122-30.

73. Morbiducci U, Ponzini R, Rizzo G, Cadioli M, Esposito A, De Cobelli F, Del Maschio A, Montevecchi FM, Redaelli A. In vivo quantification of helical blood flow in human aorta by time-resolved three-dimensional cine phase contrast magnetic resonance imaging. Ann Biomed Eng. 2009;37(3):516.

74. Jin S, Oshinski J, Giddens DP. Effects of wall motion and compliance on flow patterns in the ascending aorta. J Biomech Eng. 2003;125(3):347-54

75. Vignon-Clementel IE, Figueroa C, Jansen K, Taylor C. Outflow boundary conditions for $3 d$ simulations of nonperiodic blood flow and pressure fields in deformable arteries. Comput Methods Biomech Biomed Eng. 2010;13(5):625-40.

76. Vignon-Clementel IE, Figueroa CA, Jansen KE, Taylor CA. Outflow boundary conditions for three-dimensional finite element modeling of blood flow and pressure in arteries. Comput Methods Appl Mech Eng. 2006;195(29-32):3776-96.

77. Kim HJ, Vignon-Clementel IE, Figueroa CA, LaDisa JF, Jansen KE, Feinstein JA, Taylor CA. On coupling a lumped parameter heart model and a three-dimensional finite element aorta model. Ann Biomed Eng. 2009;37(11):215369. https://doi.org/10.1007/s10439-009-9760-8.

78. Frank O. Die grundform des arteriellen pulses. Erste Abhandlung Mathematische Analyse Z Biol. 1899;37:483-526.

79. Grinberg L, Karniadakis GE. Outflow boundary conditions for arterial networks with multiple outlets. Ann Biomed Eng. 2008;36(9):1496-514.

80. Hellevik LR. Lumped models. Cardiovasc Biomech.

81. Dean W, Hurst J. Note on the motion of fluid in a curved pipe. Mathematika. 1959;6(01):77-85.

82. Dean W. Lxxii. The stream-line motion of fluid in a curved pipe (second paper). Lond Edinb Dublin Philos Mag J Sci. 1928;5(30):673-95.

83. Myers J, Moore J, Ojha M, Johnston K, Ethier C. Factors influencing blood flow patterns in the human right coronary artery. Ann Biomed Eng. 2001;29(2):109-20.

84. Truskey GA, Yuan F, Katz DF. Transport phenomena in biological systems. Druham: Pearson/Prentice Hall Upper Saddle River NJ; 2004

85. Chandran K, Yearwood T. Experimental study of physiological pulsatile flow in a curved tube. J Fluid Mech. 1981:111:59-85

86. Talbot L, Gong K. Pulsatile entrance flow in a curved pipe. J Fluid Mech. 1983;127:1-25.

87. Hamakiotes CC, Berger SA. Fully developed pulsatile flow in a curved pipe. J Fluid Mech. 1988;195:23-55. 
88. Najjari MR, Plesniak MW. Evolution of vortical structures in a curved artery model with non-newtonian blood-analog fluid under pulsatile inflow conditions. Exp Fluids. 2016;57(6):1-16.

89. Trachet B, Bols J, De Santis G, Vandenberghe S, Loeys B, Segers P. The impact of simplified boundary conditions and aortic arch inclusion on cfd simulations in the mouse aorta: a comparison with mouse-specific reference data. J Biomech Eng. 2011;133(12):121006.

90. Renner J, Loyd D, Länne T, Karlsson M. Is a flat inlet profile sufficient for wss estimation in the aortic arch. WSEAS Trans Fluid Mech. 2009;4(4):148-60.

- fast, convenient online submission

- thorough peer review by experienced researchers in your field

- rapid publication on acceptance

- support for research data, including large and complex data types

- gold Open Access which fosters wider collaboration and increased citations

- maximum visibility for your research: over 100M website views per year

At BMC, research is always in progress.

Learn more biomedcentral.com/submissions 